\title{
Structure and $\mathrm{H}_{2}$ Sensing Property of $\mathrm{TiO}_{2}$ Sputtered Films Deposited under Various Discharge Gas Pressures
}

\author{
Dan Meng, Toshinari Yamazaki*, Toshio Kikuta and Yasuhiko Nagata \\ Graduate School of Science and Engineering, University of Toyama, \\ Gofuku 3190, Toyama 930-8555, Japan
}

(Received September 27, 2011; accepted February 24, 2012)

Key words: $\mathrm{TiO}_{2}$, thin film, $\mathrm{H}_{2}$, sputtering, surface area

$\mathrm{TiO}_{2}$ films were deposited by direct current (DC) magnetron sputtering under various discharge gas pressures. The structure of the films was investigated with focus on porosity, which was quantatitively evaluated on the basis of density and effective surface area. Furthermore, the $\mathrm{H}_{2}$ sensing property of the films was investigated at different operating temperatures in ambient air. As-deposited films were amorphous. They crystallized to be of an anatase structure by annealing at $500^{\circ} \mathrm{C}$. Films deposited under low pressure were smooth, whereas the films deposited under high pressure were composed of columnar grains. After annealing, the columnar grains were well defined, and the grain size increased with increasing annealing temperature. As the pressure during deposition increased, voids developed between columnar grains. The density decreased and the effective surface area increased with increasing pressure, indicating the formation of a porous film. A dense film deposited under low pressure showed sensitivity only at operating temperatures above $200^{\circ} \mathrm{C}$. With decreasing density caused by increasing pressure, the sensing temperature decreased. The porous film annealed at $500^{\circ} \mathrm{C}$ showed a high sensitivity even at a low temperature of $100^{\circ} \mathrm{C}$.

\section{Introduction}

Various oxide semiconductor films such as $\mathrm{SnO}_{2},{ }^{(1-5)} \mathrm{WO}_{3},{ }^{(6-9)} \mathrm{TiO}_{2},{ }^{(10-22)} \mathrm{MoO}_{3},{ }^{(23,24)}$ $\mathrm{NiO},{ }^{(25,26)} \mathrm{In}_{2} \mathrm{O}_{3},{ }^{(27,28)}$ and $\mathrm{ZnO}^{(29,30)}$ have been studied as gas-sensing materials and they demonstrated good sensing properties for detecting target gases such as $\mathrm{NO}_{x}$, $\mathrm{O}_{3}, \mathrm{NH}_{3}, \mathrm{CO}, \mathrm{H}_{2}, \mathrm{H}_{2} \mathrm{~S}$, and $\mathrm{CH}_{4}$. Of these oxide semiconductor films, $\mathrm{TiO}_{2}$, an n-type

${ }^{*}$ Corresponding author: e-mail: yamazaki@eng.u-toyama.ac.jp 
semiconductor, has recently attracted much attention because of its high durability, high chemical stability in hostile environments, and thermal stability at high temperature. ${ }^{(12)}$

$\mathrm{TiO}_{2}$ films have been formed by methods such as sputtering, ${ }^{(10-15)}$ thermal oxidation, (16) microarc oxidation, ${ }^{(17)}$ anode oxidation, ${ }^{(18)}$ dip coating, ${ }^{(19)}$ sol-gel method, ${ }^{(20,21)}$ and spray pyrolysis, ${ }^{(22)}$ and they have been studied as gas-sensing materials. For example, a macroporous $\mathrm{TiO}_{2}$ film deposited by radio frequency (RF) sputtering on a polymethacrylate-microsphere templated substrate showed a high sensitivity to $\mathrm{NO}_{2} \cdot{ }^{(11)}$ $\mathrm{A} \mathrm{TiO}_{2}$ film containing cracks, formed by thermal oxidation of a Ti plate, showed an extremely high sensitivity to $\mathrm{H}_{2} \cdot{ }^{(16)}$

For sputtered films, Thornton ${ }^{(31,32)}$ pointed out that the sputtered films deposited under a high discharge gas pressure usually have a columnar structure and the columns are surrounded by voids. As the discharge gas pressure increases, voids develop and the density of the film decreases. According to this growth model, the present authors systematically investigated the effect of the deposition conditions of $\mathrm{SnO}_{2},{ }^{(2-5)} \mathrm{WO}_{3}$, ${ }^{(7)}$ and $\mathrm{MoO}_{3}{ }^{(23)}$ sputtered films on the film structure and discussed the relationship between the film structure and gas sensitivity. They found that the film density decreased with increasing discharge gas pressure, indicating the formation of a porous film. The sensitivity increased as the film density decreased, that is, a porous film showed a high sensitivity. Although there have been some reports of gas sensors made of $\mathrm{TiO}_{2}$ sputtered films, ${ }^{(10-15)}$ no systematic investigation of the gas sensing property of the films deposited under various discharge gas pressures in relationship to the film structure has been reported. Thus, in this study, we investigated the effect of discharge gas pressures on the $\mathrm{TiO}_{2}$ film structure and discussed the relationship between the film structure and $\mathrm{H}_{2}$ sensing property.

In this study, $\mathrm{TiO}_{2}$ films were deposited by direct current (DC) magnetron sputtering under various discharge gas pressures. The film structure was studied by X-ray diffraction (XRD), field emission scanning electron microscopy (FE-SEM), and measurement of density and effective surface area. The measurements of density and effective surface area are quantitive and reliable techniques to evaluate the porosity of thin films. $\mathrm{H}_{2}$ sensing properties were investigated at different operating temperatures in ambient air.

\section{Experimental Methods}

$\mathrm{TiO}_{2}$ films were deposited on an oxidized Si substrate at room temperature by DC magnetron sputtering. A circular Ti target of $100 \mathrm{~mm}$ diameter with a purity of $99.99 \%$ was used. The discharge gas was an argon-oxygen mixture with a ratio of $\mathrm{Ar} / \mathrm{O}_{2}=1: 1$. The discharge gas pressure was fixed at $0.6,4$, or $12 \mathrm{~Pa}$. The discharge voltage was changed from 420 to $400 \mathrm{~V}$ depending on the pressure, while the discharge current was fixed at $0.2 \mathrm{~A}$. The film thickness was approximately $500 \mathrm{~nm}$. After deposition, the films were annealed at $500^{\circ} \mathrm{C}$ for $1 \mathrm{~h}$ in air. For the measurement of gas sensing properties, the films were deposited on an oxidized Si substrate of $15 \times 15 \mathrm{~mm}^{2}$ size equipped with a pair of interdigitated Pt electrodes with a gap length of $35 \mu \mathrm{m}$. The size of the sensing element was $7 \times 10 \mathrm{~mm}^{2}$. To stabilize the sensing properties, the sensors were annealed 
at $500^{\circ} \mathrm{C}$ for $1 \mathrm{~h}$ in air. To investigate the effect of annealing temperature on the film structure and sensing property, the film deposited at $12 \mathrm{~Pa}$ was annealed at $450-600^{\circ} \mathrm{C}$ for $1 \mathrm{~h}$ in air.

The crystallographic structure of the films was analyzed using an X-ray diffractometer (Shimadzu XRD-6100) with $\mathrm{Cu}-\mathrm{K} \alpha$ radiation. The morphologies of the surface and cross section were observed using an FE-SEM (JEOL JFM6700F). The film density was determined by measuring the thickness and mass of the films of $20 \times 20 \mathrm{~mm}^{2}$ size. A surface roughness tester (Tokyo Seimitsu Surfcom 1500DX) was used for the measurement of the thickness. The mass of the films was determined by measuring the masses of a sample before and after $\mathrm{TiO}_{2}$ film deposition by using an electric balance (Metter Toled MT-5). Because the measurement error of the thickness and mass for the films about $500 \mathrm{~nm}$ in thickness and 500-700 $\mu \mathrm{g}$ in mass were $5 \mathrm{~nm}$ and $2 \mu \mathrm{g}$, respectively, the uncertainty of the measured density was about $1.3 \%$. The effective surface areas were determined using a physical adsorption apparatus (Quantachrome AUTOSORB-1-MP). In this measurement, to obtain a large film area, films were deposited on the front and rear surfaces of a 4 in. Si wafer, both sides of which were mirror-polished and oxidized. About 50 strips of $20 \times 5 \mathrm{~mm}^{2}$ size were cut out of the wafer and were introduced into a sample cell of the apparatus. $\mathrm{Kr}$ gas with a low saturation vapor pressure of $236 \mathrm{~Pa}$ at liquid nitrogen temperature was used as an adsorption gas for a precise measurement. This procedure enabled the measurement of the surface area of $100 \mathrm{~mm}^{2}$ at an uncertainty smaller than $10 \%$. More details of this measurement are described in ref. 3. The investigation of the film structure mentioned above was performed for both as-deposited and annealed films.

The sensing property was measured for sensors placed in an aluminum vessel with a capacity of 13.2 L filled with ambient air. The sensor resistance was determined by measuring the current that flowed when an electric voltage of $10 \mathrm{~V}$ was applied between the Pt electrodes. The change in resistance upon introduction of $\mathrm{H}_{2}$ at $2000 \mathrm{ppm}$, which was introduced using an injector, was measured from room temperature to $400^{\circ} \mathrm{C}$. The sensitivity was defined as $\left(R_{\text {air }}-R_{\text {gas }}\right) / R_{\text {gas }}$, where $R_{\text {air }}$ and $R_{\text {gas }}$ are the resistance before and after the introduction of $\mathrm{H}_{2}$, respectively.

\section{Results and Discussion}

X-ray diffraction patterns for as-deposited and annealed films are shown in Figs. 1(a) and 1(b). The as-deposited films are amorphous, irrespective of the discharge gas pressure. After annealing at $500^{\circ} \mathrm{C}$, the films exhibit peaks characteristic of anatase. The film deposited at $0.6 \mathrm{~Pa}$ exhibits a preferential orientation of (101), whereas the films deposited at 4 and $12 \mathrm{~Pa}$ exhibit preferential orientation of the tetragonal $\mathrm{c}$ plane.

Figure 2 shows the surface and cross-sectional FE-SEM images of as-deposited and annealed films under various discharge gas pressures. The film as-deposited under a low pressure of $0.6 \mathrm{~Pa}$ is rather smooth. After annealing, although the surface of this film shows little change in appearance, grains are observed in the cross-sectional FE-SEM image. In the films as-deposited under higher pressures of 4 and $12 \mathrm{~Pa}$, grains and thin cracks are observed. According to their cross-sectional FE-SEM images, these grains are 

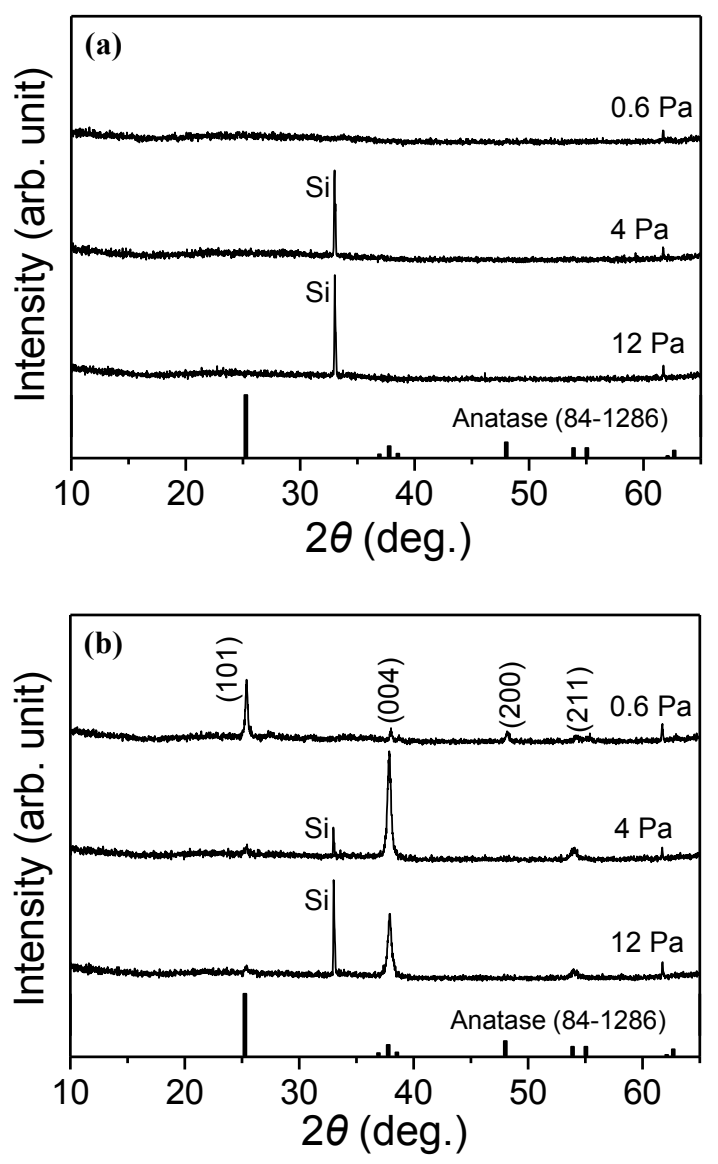

Fig. 1. XRD patterns of $\mathrm{TiO}_{2}$ films (a) as-deposited and (b) annealed at $500^{\circ} \mathrm{C}$. The discharge gas pressures are indicated in the figure.

columnar. After annealing, the columnar grains are well defined, and many wide cracks owing to the shrinkage of the films are observed. In the film deposited at $4 \mathrm{~Pa}$, the grain size increases from 10-20 to 30-50 nm after annealing, while in the film deposited at 12 $\mathrm{Pa}$, the grain size increases from $5-15$ to $20-30 \mathrm{~nm}$ after annealing.

The densities of the as-deposited and annealed films are shown in Fig. 3. The relative surface area (effective surface area divided by substrate area) is also shown in this figure. For both as-deposited and annealed films, owing to the formation of vacancies and voids during the deposition, ${ }^{(31-33)}$ the densities of the films deposited under various discharge gas pressures are lower than the bulk density of $\mathrm{TiO}_{2}$. The decrease in density with increasing pressure is due to the development of voids. Here, note that the density 


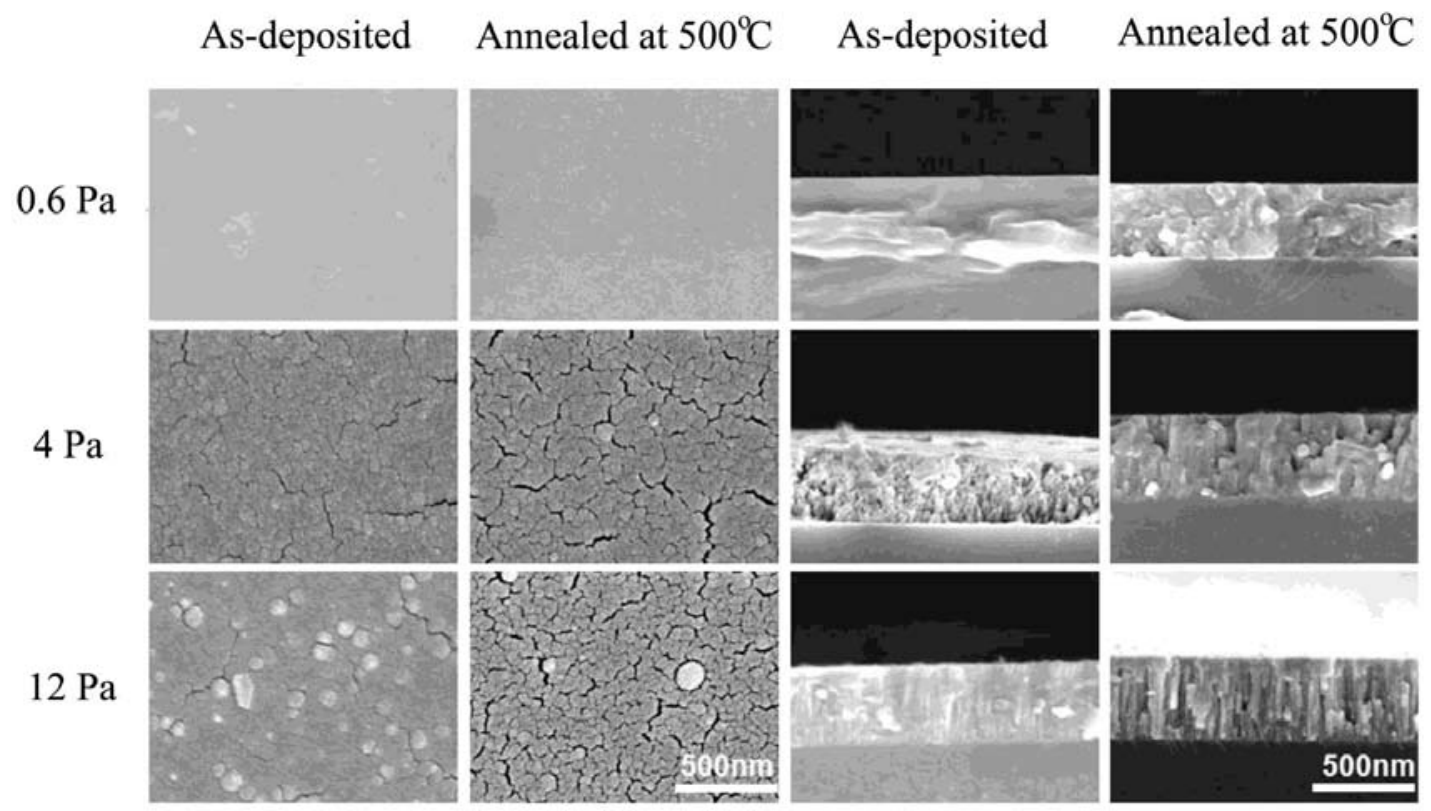

Fig. 2. Surface and cross-sectional FE-SEM images of as-deposited films and annealed films deposited under various discharge gas pressures.

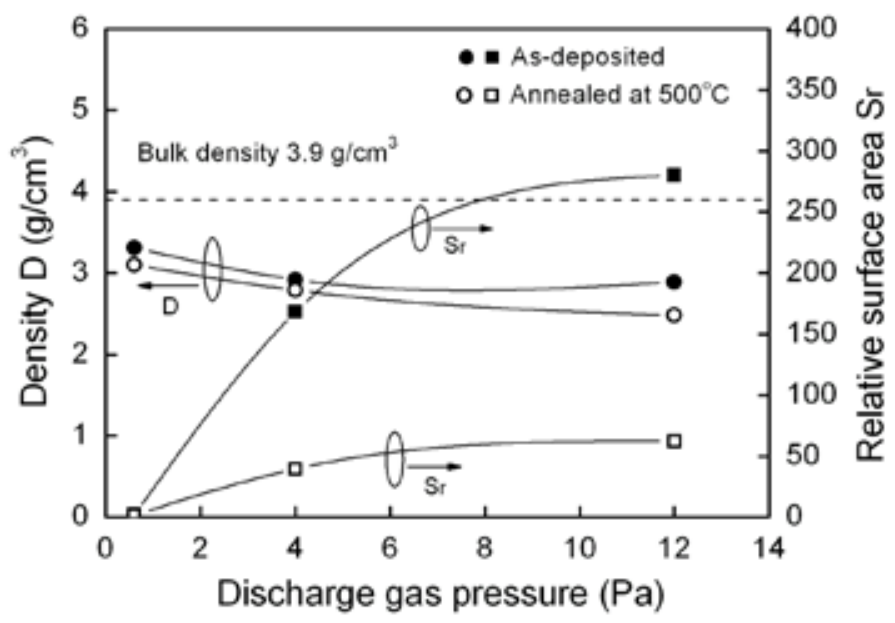

Fig. 3. Density and relative surface area of as-deposited films and annealed films as functions of the discharge gas pressure. 
of the annealed films being slightly smaller than that of the as-deposited films is due to a decrease in mass after annealing and is not due to a change in thickness; the thickness of a film after annealing agreed with that before annealing within a measurement error of $5 \mathrm{~nm}$. The decrease in mass seems to be due to the release of $\mathrm{Ar}$ and $\mathrm{O}_{2}$ molecules adsorbed on grains composing the films or included in the films and the release of $\mathrm{H}_{2} \mathrm{O}$ molecules adsorbed on the surface. The relative surface area increases with increasing pressure for both as-deposited films and annealed films. Assuming that the porous film deposited at $12 \mathrm{~Pa}$ is composed of columns $8 \mathrm{~nm}$ thick and $500 \mathrm{~nm}$ high, we can calculate the ratio of the surface area of a column (the sum of the area of the top surface and that of the sidewall) divided by the area of its top surface to be 251 , which is approximately equal to the relative surface area of 276 . This fact demonstrates that most columns are surrounded by voids. Thus, the film deposited at a high pressure shows a large surface area. Although the relative surface area decreases after annealing, it is still much larger than the geometrical surface area for the films deposited at 4 and $12 \mathrm{~Pa}$.

An example of the change in the resistance of the film deposited at $0.6 \mathrm{~Pa}$ upon introduction of $\mathrm{H}_{2}$ is shown in Fig. 4. The operating temperature is $300^{\circ} \mathrm{C}$. The resistance rapidly decreases upon introduction of $\mathrm{H}_{2}$ and gradually recovers to the initial value after the exhaust of $\mathrm{H}_{2}$. This behavior of the resistance was observed two times with a good reproducibility as shown in the figure.

Figure 5 shows the temperature dependence of the resistance before (solid line) and after (dotted line) the introduction of $\mathrm{H}_{2}$ in ambient air while Fig. 6 shows that in dry air not including $\mathrm{H}_{2}$. The resistance of the porous film in ambient air is lower than that in dry air at all temperatures examined. On the other hand, the resistance of the

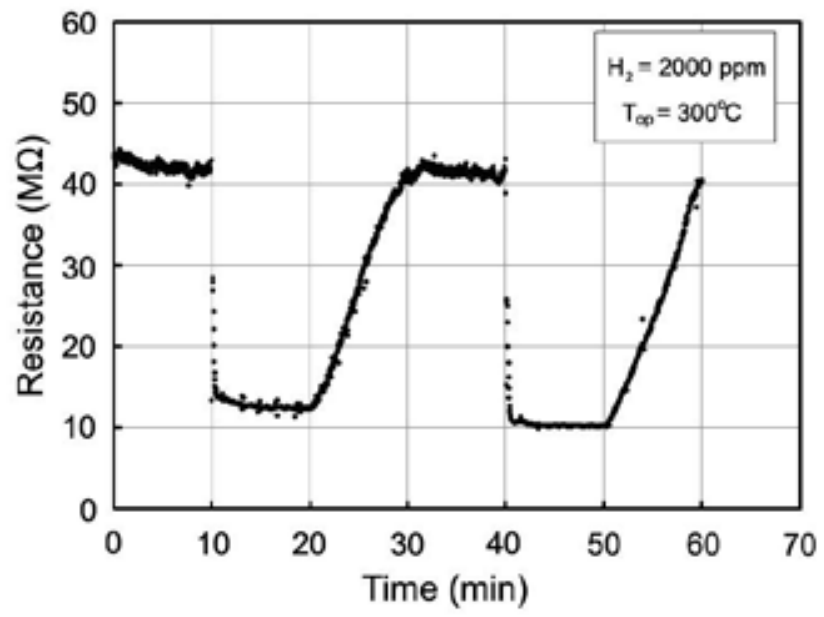

Fig. 4. Temporal responses of a sensor made of $\mathrm{TiO}_{2}$ films deposited at $0.6 \mathrm{~Pa}$ to $\mathrm{H}_{2}$ at $2000 \mathrm{ppm}$. The operating temperature was $300^{\circ} \mathrm{C}$. 


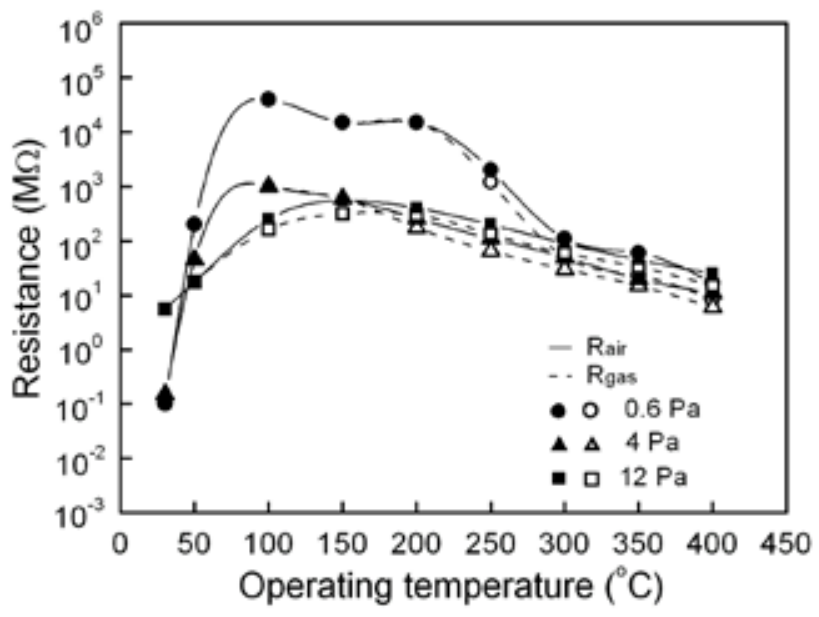

Fig. 5. Temperature dependence of resistance of $\mathrm{TiO}_{2}$ films deposited under various discharge gas pressures in ambient air.

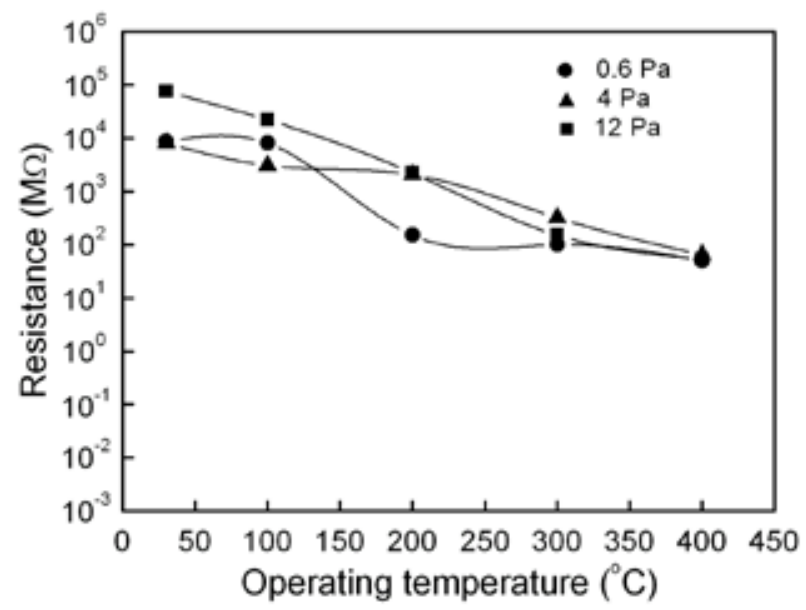

Fig. 6. Temperature dependence of resistance of $\mathrm{TiO}_{2}$ films deposited under various discharge gas pressures in dry air. 
dense film in ambient air is lower than that in dry air only at temperatures below $100^{\circ} \mathrm{C}$. The resistance of the porous film is lower than that of the dense film especially at low temperatures. These phenomena can be explained by the humidity effect in ambient air, namely, water adsorption reducing the resistance. ${ }^{(34-36)}$ The porous film with many voids can adsorb much water, resulting in a low resistance. It is reported that the adsorption of water on the oxide surface results in the formation of molecular water at low temperature and hydroxyl groups at high temperature. ${ }^{(36,37)}$ Therefore, the decrease in resistance of all films with decreasing temperature below $100^{\circ} \mathrm{C}$ can be ascribed to the adsorption of molecular water.

Figure 7 shows the temperature dependence of the sensitivity of $\mathrm{TiO}_{2}$ films deposited under three different pressures. The dense film with a density of $3.1 \mathrm{~g} / \mathrm{cm}^{3}$ shows a response only in the temperature region above $200^{\circ} \mathrm{C}$, whereas the porous film with a density of $2.5 \mathrm{~g} / \mathrm{cm}^{3}$ shows a high sensitivity at $100^{\circ} \mathrm{C}$. As the film density decreases, the film shows a response in a lower temperature region. This low-temperature operation is favourable for power saving and device integration. A similar behavior was also observed in $\mathrm{SnO}_{2}$ films. ${ }^{(5)}$ A porous $\mathrm{SnO}_{2}$ film showed a higher sensitivity than a dense $\mathrm{SnO}_{2}$ film at all the temperatures examined. However, a porous $\mathrm{TiO}_{2}$ film unexpectedly showed a lower sensitivity than a dense $\mathrm{TiO}_{2}$ film at temperatures above $250^{\circ} \mathrm{C}$. To examine the reproducibility of this result, we made another set of three sensors and measured their sensing properties. Thus, we confirmed the reproducibility of this result.

It is possible that humidity affects the sensing property of dense and porous films. Pavelko et al. ${ }^{(38)}$ described the action of $\mathrm{H}_{2}$ on $\mathrm{SnO}_{2}$ in the presence of humidity

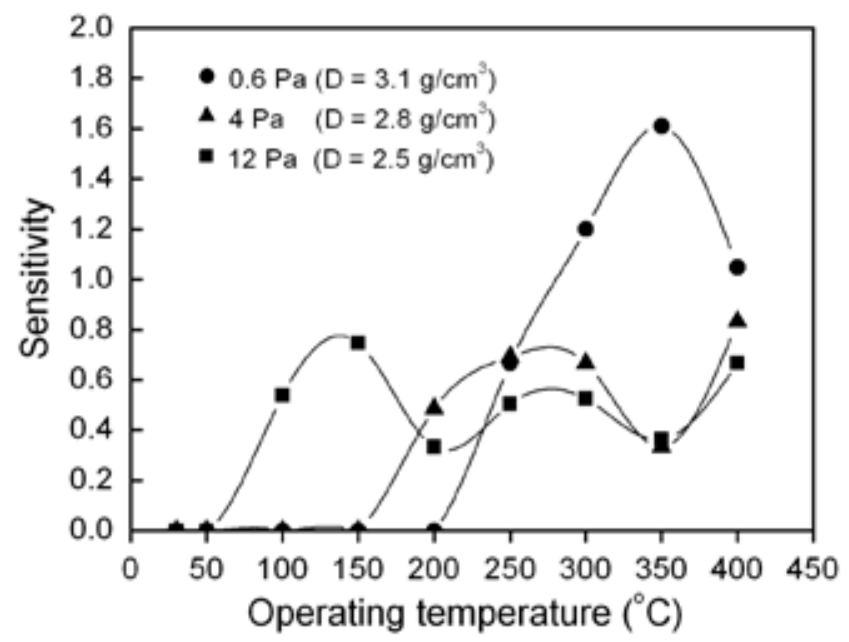

Fig. 7. Temperature dependence of sensitivity of $\mathrm{TiO}_{2}$ films deposited under various discharge gas pressures. 
and reported that the sensitivity decreased with increasing relative humidity. In our measurement, the formation of molecular water or hydroxyl groups affects the resistance behavior of porous and dense films, as shown in Fig. 5, which implies that the sensitivity may also be affected by the humidity. It is generally accepted that $\mathrm{H}_{2}$ sensing mechanism is the reaction of $\mathrm{H}_{2}$ with oxygen species, which releases the electron adsorbed by oxygen species back to the conduction band, resulting in a decrease in the resistance, as shown in Fig. 5. The porous film with a large surface area can adsorb much oxygen and $\mathrm{H}_{2}$, which activates the reaction of $\mathrm{H}_{2}$ with oxygen species, resulting in a high sensitivity. However, a low sensitivity was observed in the porous film at high temperature. As mentioned above, the humidity controls the resistance behavior of the porous film at high temperature, which implies that hydroxyl groups may interfere with the adsorption of oxygen species. If it is true, it can be suggested that hydroxyl groups control the surface site occupation ${ }^{(39)}$ and inhibit the reaction of $\mathrm{H}_{2}$ with oxygen species, resulting in a low sensitivity of the porous film at high temperature. On the other hand, the dense film shows a high sensitivity at high temperature. From the resistance behavior of the dense film, it is known that at high temperature, hydroxyl groups may not exist in the dense film. Therefore, we suppose that the detection of $\mathrm{H}_{2}$ may occur without the existence of hydroxyl groups at high temperature. A high sensitivity of the dense film may be due to thermally activating the reaction of $\mathrm{H}_{2}$ with oxygen species at high temperature. Here, it should be pointed that what surface processes account for the sensitivity to $\mathrm{H}_{2}$ on $\mathrm{TiO}_{2}$ in the presence of humidity is not clear. The investigation of the sensing property in controlled humidity is necessary, which will be studied in the near future.

The effect of annealing temperature on the film structure and sensing property is discussed for the porous film deposited at $12 \mathrm{~Pa}$. The density and relative surface area decrease with increasing annealing temperature as shown in Fig. 8. The decrease in density is ascribed to the decrease in film mass. On the other hand, the increase in size of columnar grains with increasing annealing temperature causes the decrease in the relative surface area. According to the FE-SEM images shown in Fig. 9, many wide cracks owing to the shrinkage of the films were observed at a high annealing temperature. The width of the cracks increases with increasing annealing temperature.

The temperature dependence of the sensitivity of porous films annealed at different temperatures is shown in Fig. 10. The film annealed at $500^{\circ} \mathrm{C}$ shows a high sensitivity at a low temperature. This high sensitivity may be due to a high relative surface area. Although the relative surface area of the film annealed at $450^{\circ} \mathrm{C}$ is higher than that of the film annealed at $500^{\circ} \mathrm{C}$, the film annealed at $450^{\circ} \mathrm{C}$ shows a lower sensitivity at a low temperature, which may be due to the effect of humidity. At a high annealing temperature of $550^{\circ} \mathrm{C}$, the columnar grains coalesce with each other, causing the increase in the columnar grain size. The structure of the film annealed at $550^{\circ} \mathrm{C}$ is similar to that of the dense film deposited at a low discharge gas pressure. Therefore, the film annealed at $550^{\circ} \mathrm{C}$ shows a lower sensitivity. 


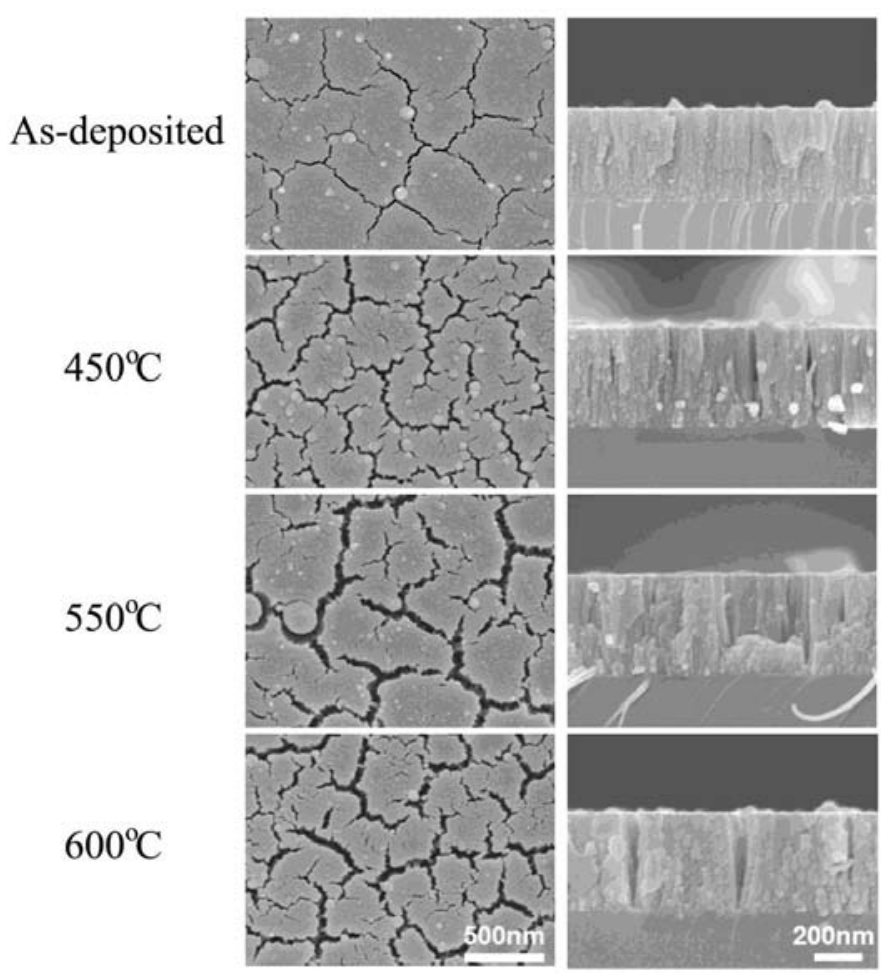

Fig. 8. Density and relative surface area as functions of annealing temperature. The $\mathrm{TiO}_{2}$ films were deposited at $12 \mathrm{~Pa}$.

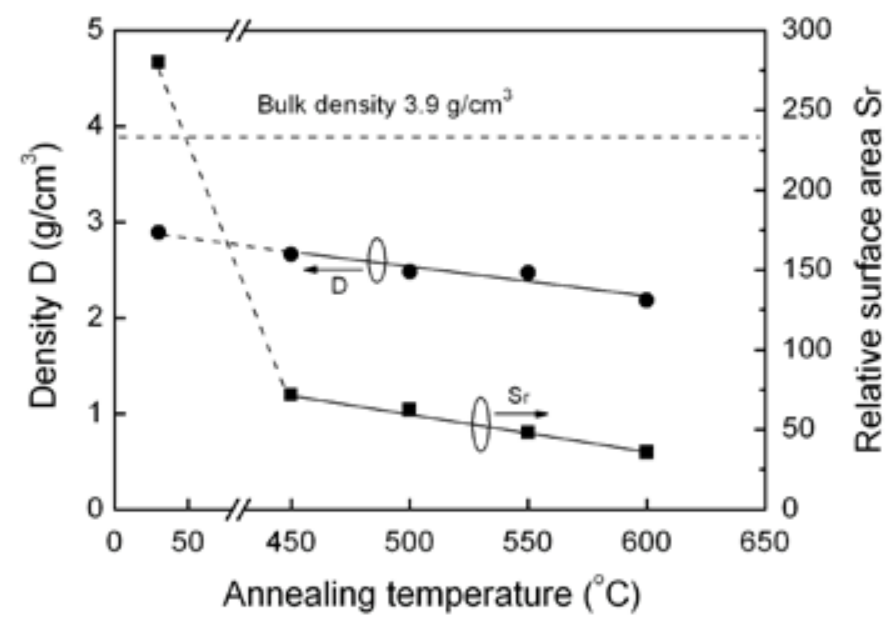

Fig. 9. Surface and cross-sectional FE-SEM images of $\mathrm{TiO}_{2}$ films deposited at $12 \mathrm{~Pa}$ and annealed at different temperatures. 


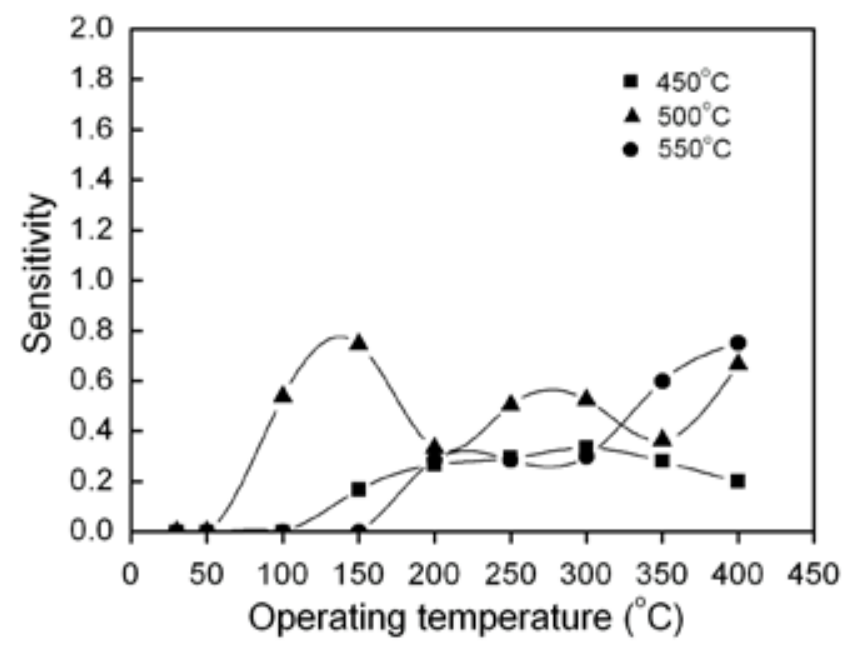

Fig. 10. Temperature dependence of sensitivity of $\mathrm{TiO}_{2}$ films annealed at different temperatures. The films were deposited at $12 \mathrm{~Pa}$.

\section{Conclusions}

$\mathrm{TiO}_{2}$ films were deposited by DC magnetron sputtering under various discharge gas pressures. The film structure was studied by XRD, FE-SEM, measurement of density, and measurement of effective surface area. The sensing property to $\mathrm{H}_{2}$ at $2000 \mathrm{ppm}$ in ambient air was measured from room temperature to $400^{\circ} \mathrm{C}$. The results obtained are summarized as follows.

As-deposited films are amorphous. They crystallize to be of an anatase structure by annealing at $500^{\circ} \mathrm{C}$. Films deposited at a low pressure are rather smooth, whereas the films deposited at a high pressure are composed of columnar grains. After annealing, the columnar grains are well defined, and the grain size increases with increasing annealing temperature. As the pressure increases, the film density decreases and the surface area increases, which indicates the development of voids between columnar grains. A dense film deposited at a low pressure of $0.6 \mathrm{~Pa}$ and annealed at $500^{\circ} \mathrm{C}$ shows sensitivity only above $200^{\circ} \mathrm{C}$. On the other hand, a porous film deposited at a high pressure of $12 \mathrm{~Pa}$ and annealed at $500^{\circ} \mathrm{C}$ shows a high sensitivity even at a low temperature of $100^{\circ} \mathrm{C}$. This low-temperature operation is important with respect to the reduction of electric power consumption. The investigation of sensing properties under controlled humidity should be performed to understand the effect of humidity on the $\mathrm{H}_{2}$ detection mechanism. 


\section{Acknowledgements}

The authors would like to acknowledge the support of the Venture Business Laboratory of the University of Toyama.

\section{References}

1 A. Karthigeyan, R. P. Gupata, K. Scharnagl, M. Burgmair, M. Zimmer, S. K. Sharma and I. Eisele: Sens. Actuators, B 78 (2001) 69.

2 T. Yamazaki, H. Okumura, C. J. Jin, A. Nakayama, T. Kikuta and N. Nakatani: Vacuum 77 (2005) 237.

3 T. Yamazaki, T. Furuta, Y. B. Shen, C. J. Jin, T. Kikuta and N. Nakatani: Jpn. J. Appl. Phys. 45 (2006) 9180.

4 T. Yamazaki, C. J. Jin, Y. B. Shen, T. Kikuta and N. Nakatani: Mater. Sci. Forum 539-543 (2007) 3508.

5 Y. B. Shen, T. Yamazaki, Z. F. Liu, C. J. Jin, T. Kikuta and N. Nakatani: Thin Solid Films 516 (2008) 5111

6 M. Akiyama, J. Tamaki, N. Miura and N. Yamazoe: Chem. Lett. 20 (1991) 1611.

7 C. J. Jin, T. Yamazaki, Y. Shirai, T. Yoshizawa, T. Kikuta, N. Nakatani and H. Takeda: Thin Solid Films 474 (2005) 255.

8 D. Meng, T. Yamazaki, Y. B. Shen, Z. F. Liu and T. Kikuta: Appl. Surf. Sci. 256 (2009) 1050.

9 M. Hübner, C. E. Simion, A. Haensch, N. Barsan and U. Weimar: Sens. Actuators, B 151 (2010) 103.

10 I. A. Al-Homoudi, J. S. Thakur, R. Naik, G. W. Auner and G. Newaz: Appl. Surf. Sci. 253 (2007) 8607.

11 Il. D. Kim, A. Rothschild, D. J. Yang and H. L. Tuller: Sens. Actuators, B 130 (2008) 9.

12 D. Mardare, N. Iftimie and D. Luca: J. Non-Cryst. Solids 354 (2008) 4396.

13 Y. Yamada, Y. Seno, Y. Masuoka, T. Nakamura and K. Yamashita: Sens. Actuators, B 66 (2000) 164.

14 W. T. Moon, K. S. Lee, Y. K. Jun, H. S. Kim and S. H. Hong: Sens. Actuators, B 115 (2006) 123.

15 P. K. Dutta, M. Frank, G. W. Hunter and M. George: Sens. Actuators, B 106 (2005) 810.

16 Y. K. Jun, H. S. Kim, J. H. Lee and S. H. Hong: Sens. Actuators, B 107 (2005) 264.

17 Y. K. Jun, H. S. Kim, J. H. Lee and S. H. Hong: Sens. Actuators, B 120 (2006) 69.

18 Y. Shimizu, T. Hyodo and M. Egashira: Sens. Actuators, B 121 (2007) 219.

19 L. P. Sun, L. H. Huo, H. Zhao, S. Gao and J. G. Zhao: Sens. Actuators, B 114 (2006) 387.

20 C. Garzella, E. Comini, E. Tempesti, C. Frigeri and G. Sberveglieri: Sens. Actuators, B 68 (2000) 189.

21 L. Francioso, D. S. Presicce, M. Epifani, P. Siciliano and A. Ficarella: Sens. Actuators, B 107 (2005) 563.

22 A. M. More, J. L. Gunjakar and C. D. Lokhande: Sens. Actuators, B 129 (2008) 671.

23 T. Yamazaki, C. J. Jin, A. Nakayama, K. Ito, T. Yoshizawa, T. Kikuta, N. Nakatani and T. Yamabuchi: Jpn. J. Appl. Phys. 44 (2005) 792.

24 S. Barazzouk, R. P. Tandon and S. Hotchandani: Sens. Actuators, B 119 (2006) 691.

25 J. A. Dirksen, K. Duval and T. A. Ring: Sens. Actuators, B 80 (2001) 106.

26 C. Luyo, R. Ionescu, L. F. Reyes, Z. Topalian, W. Estrada, E. Llobet, C. G. Granqvist and P. Heszler: Sens. Actuators, B 138 (2009) 14.

27 T. Takada, H. Tanjou, T. Saito and K. Harada: Sens. Actuators, B 24 (1995) 548. 
28 C. Cantalini, W. Wlodarski, H. T. Sun, M. Z. Atashbar, M. Passacantando and S. Santucci: Sens. Actuators, B 65 (2000) 101.

29 N. Koshizaki and T. Oyama: Sens. Actuators, B 66 (2000) 119.

30 M. W. Ahn, K. S. Park, J. H. Heo, D. W. Kim, K. J. Choi and J. G. Park: Sens. Actuators, B 138 (2009) 168.

31 J. A. Thornton: J. Vac. Sci. Technol. A 4 (1986) 3059.

32 J. A. Thornton: J. Vac. Sci. Technol. 11 (1974) 666.

33 S. Nakahara: Thin Solid Films 64 (1979) 149.

34 D. B. Dimitrov, J. Koprinarova, J. Pazov and Ch. Angelov: Vacuum 58 (2000) 344.

35 J. F. Boyle and K. A. Jones: J. Electron. Mater. 6 (1977) 717.

36 N. Barsan and U. Weimar: J. Electroceram. 7 (2001) 143.

37 E. W. Thornton and P. G. Harrison: J. Chem. Soc. Faraday Trans. 171 (1975) 2468.

38 R. G. Pavelko, A. A. Vasiliev, E. Llobet, X. Vilanova, X. Correig and V. G. Sevastyanov: Olfaction and Electronic Nose: Proceedings of the 13th International Symposium on Olfaction and Electronic Nose (American Institute of Physics, Melville, 2009) p. 29.

39 G. Korotcenkov, V. Brinzari, V. Golovanov and Y. Blinov: Sens. Actuators, B 98 (2004) 41. 